\title{
Radio Silence
}

\section{Autonomous Military Aircraft and the Importance of Communication for their Use in Peace Time and in Times of Armed Conflict under International Law}

Eve Massingham

\begin{abstract}
Aerial systems with autonomous functionality are not new. However, their prevalence, sizes, manoeuvrability and the altitudes at which they fly today have not been fully contemplated by the international legal frameworks for aircraft developed in the 20th century. States are increasingly deploying these craft to undertake a range of tasks, and while these activities were once somewhat separated from the civilian airspace, this is no longer always the case. While most international civil aviation rules do not apply to military aircraft, military aircraft are not entirely exempt from compliance with key rules necessary to ensure the safety of civil aviation. This paper looks at how autonomous military aircraft are impacted by laws to protect international civil aviation, and indeed, civilians, and in particular identifies some of the communication requirements for the safe and lawful use of autonomous military aircraft alongside civil aviation, both in peace time and in times of armed conflict.
\end{abstract}

Dr Eve Massingham is a Senior Research Fellow in the Law and the Future of War research group at the University of Queensland. [e.massingham@uq.edu.au].

The research for this paper received funding from the Australian Government through the Defence Cooperative Research Centre for Trusted Autonomous Systems. The views and opinions expressed in the paper are those of the author, and do not necessarily reflect the views of the Australian Government or any other institution. The author wishes to thank Simon McKenzie, Rain Liivoja and the anonymous reviewers for their helpful comments.

This paper appeared in (2020) 1(1) Asia-Pacific Journal of International Humanitarian Law 184-208. 


\section{Contents}

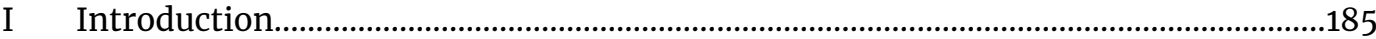

II Autonomous Functionality in Aircraft..........................................................................186

III International Legal Frameworks for Military Aircraft with Autonomous

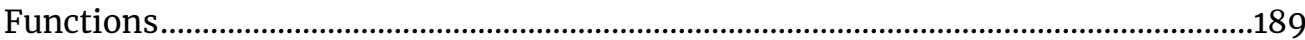

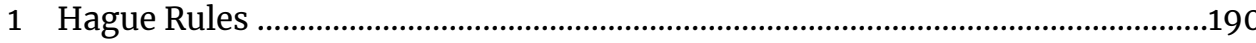

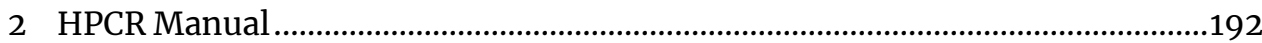

3 Chicago Convention .............................................................................................193

4 Military Aircraft with Autonomous Functions.......................................................194

IV Autonomous State Aircraft and the Safety of Civil Aviation .......................................197

V Autonomous State Aircraft and Navigation Rights....................................................201

VI Military Aircraft Rights and Obligations under International Humanitarian Law and Communication in Aid of Civilian Safety...................................................................204

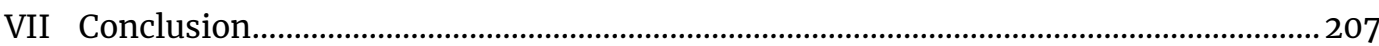




\title{
Radio Silence: Autonomous Military Aircraft and the Importance of Communication for their Use in Peace Time and in Times of Armed Conflict under International Law
}

\author{
Dr. Eve Massingham*
}

\begin{abstract}
Aerial systems with autonomous functionality are not new. However, their prevalence, sizes, manoeuvrability and the altitudes at which they fly today have not been fully contemplated by the international legal frameworks for aircraft developed in the $20^{\text {th }}$ century. States are increasingly deploying these craft to undertake a range of tasks, and while these activities were once somewhat separated from the civilian airspace, this is no longer always the case. While most international civil aviation rules do not apply to military aircraft, military aircraft are not entirely exempt from compliance with key rules necessary to ensure the safety of civil aviation. This paper looks at how autonomous military aircraft are impacted by laws to protect international civil aviation, and indeed, civilians, and in particular identifies some of the communication requirements for the safe and lawful use of autonomous military aircraft alongside civil aviation, both in peace time and in times of armed conflict.
\end{abstract}

Keywords: International Law; Communication, Aircraft; State Aircraft; Military Aircraft; Autonomous Aircraft; Safety; Navigation; Belligerent Rights; International Humanitarian Law.

Senior Research Fellow in the Law and the Future of War research group at the University of Queensland. Prior to her current role Eve worked for the International Red Cross and Red Crescent Movement for 10 years as a legal adviser - primarily throughout East Africa and in Australia. She has published a number of book chapters and articles on international humanitarian law and is the co-editor of Ensuring Respect for Intentional Humanitarian Law (Routledge, 2020).

The research for this paper received funding from the Australian Government through the Defence Cooperative Research Centre for Trusted Autonomous Systems. The views and opinions expressed in the paper are those of the author, and do not necessarily reflect the views of the Australian Government or any other institution. The author wishes to thank Simon McKenzie, Rain Liivoja and the anonymous reviewers for their helpful comments. 


\section{Introduction}

Militaries are keen to exploit autonomous technology. This is both to allow States to achieve their military objectives with potentially less risk to their people and expensive military hardware and assets than other methods, and to ensure that they are able to counter the technology deployed against them. Military systems with autonomous functionality are not new. ${ }^{1}$ However, in recent years, autonomous technology has proliferated and advanced. There is a significant role that autonomy is increasingly playing for the military across a range of platforms. The potential development of more advanced autonomous weapons systems by the military has led to significant global discussion about the ability of autonomous weapons to comply with the core principles of international humanitarian law. ${ }^{2}$ What receives less attention is the autonomous military platforms themselves. One of the clear advantages of autonomy is to allow the military to operate in communications-denied environments. Communication is central to military operations but is very susceptible to disruption and interception. Autonomous military aircraft are able to address this through "reduc[ing] the vulnerability of the communications link by severing it." ${ }^{3}$ The technology can "render constant control and communication links obsolete" and therefore provide protection against hijacking or jamming. ${ }^{4}$ However, to have clearance to fly, military aircraft must ensure that they can safely interact in the civilian environment. The inability of military aircraft to communicate in such a way as to "heed and care for the safety of the

1 For a more detailed look at the history of the use of autonomy by the military, see further Brendan Gogarty and Meredith Hagger, "The laws of man over vehicles unmanned: the legal response to robotic revolution on sea, land and air", Journal of Law, Information and Science, Vol. 19, 2013, pp. 76-82.

2 Group of Government Experts on Emerging Technologies in the Area of Lethal Autonomous Weapons Systems established at the 2016 Fifth Convention on the Prohibitions or Restriction on the Use of Certain Conventional Weapons Which May Be Deemed to Be Excessively Injurious or to Have Indiscriminate Effects Review Conference.

3 Kenneth Anderson and Matthew C. Waxman, "Law and Ethics for Autonomous Weapon Systems: Why a Ban Won't Work and How the Laws of War Can", The Hoover Institution Jean Perkins Task Force on National Security \& Law Essay Series, 2013, available at: https://scholarship.law.columbia.edu/faculty_scholarship/1803 (all internet references were accessed on 18 June 2020).

4 Jürgen Altmann and Frank Sauer, "Autonomous Weapon Systems and Strategic Stability", Survival, Vol. 59, No. 5, 2017, p. 119. 
course and position of civil aircraft avoiding obstruction to the course of and collisions with civil aircraft" ${ }^{2}$ means that the full benefits of the autonomous military aircraft advantage may not be exploited.

To examine these issues, this paper looks at how autonomous military aircraft are impacted by laws that aim to protect international civil aviation, as well as other relevant sources for the regulation of military aircraft. It shows the centrality of the role of communication in the safe and lawful use of autonomous military aircraft, in both peacetime and during times of armed conflict. In doing so, it considers:

- the obligation of State aircraft to have due regard for the safety of civil aviation;

- the restrictions on freedom of navigation attached to State aircraft; and

- the exercise of belligerent rights by autonomous military aircraft as they pertain to non-military persons and objects.

The paper will first discuss the nature of autonomous functionality and the different legal frameworks applicable to autonomous military aircraft before turning to look at these three topics.

\section{Autonomous Functionality in Aircraft}

There is no agreed definition of what amounts to "autonomous" aircraft. As the United Kingdom Department of Defence notes (in relation to weapons, though equally applicable across military platforms including aircraft), "there is inaccurate reporting and misleading debate about the meaning of automated and autonomous." ${ }^{6}$ Ekelhof puts it nicely when she states that, "sometimes distinctions are made when there is no actual difference, but mostly the terms are used without difference when distinction is in fact necessary."7 Autonomy clearly exists on a spectrum.

5 Michel Bourbonniere and Louis Haeck, "Military Aircraft and International Law: Chicago Opus 3", Journal of Air Law and Commerce, Vol. 66, No. 3, 2001, p. 916.

6 United Kingdom Ministry of Defence, Joint Doctrine Publication 0-30.2 Unmanned Aircraft Systems, Development, Concepts and Doctrine Centre, Swindon, August 2017, p. 42.

7 Merel Ekelhof, The Distributed Conduct of War: Reframing Debates on Autonomous Weapons, Human Control and Legal Compliance in Targeting, Vrije University, $\mathrm{PhD}$ Thesis, 2019, p. 74. 
Aircraft have a range of different functions and the move has been towards automating some of these functions to different degrees. Indeed, of aviation more generally, the observation has been made that, "most flights can only be performed adequately with the aid of automation." ${ }^{8}$ When parts of the functionality of an aircraft are able to be carried out autonomously, then that aircraft has a degree of autonomy. Experts looking at autonomy in different fields often use "levels of autonomy" to explain the different activities that autonomy can perform within the broader system. ${ }^{9}$ This "levels of autonomy" approach has however been criticized for "deflect[ing] focus from the fact that all autonomous systems are joint human-machine cognitive systems." ${ }^{10}$ Militaries have tended to focus more on the distinction between:

- remotely piloted systems, where the system is still fully controlled by an operator;

- automated systems that, "in response to inputs from one or more sensors, is programmed to logically follow a predefined set of rules in order to provide an outcome"; and

- autonomous systems that are "capable of understanding higher-level intent and direction... to take appropriate action to bring about a desired state... deciding a course of action, from a number of

8 Pablo Mendes de Leon, Introduction to Air Law, Wolters Kluwer, Alphen aan den Rijn, 2017, p. 302.

9 See for example Dale Richards and Alex Stedmon, "To delegate or not to delegate: A review of control frameworks for autonomous cars", Applied Ergonomics, Vol. 53 B, March 2016, pp. 385-386; Guang-Zhong Yang et al., "Medical robotics-Regulatory, ethical, and legal considerations for increasing levels of autonomy", Science Robotics, 15 March 2017; Charles Hewitt et al., "Assessing Public Perception of Self-Driving Cars: the Autonomous Vehicle Acceptance Model", in 24th International Conference on Intelligent User Interfaces, Marina del Ray, 17-20 March 2019.

${ }^{10}$ Department of Defence (United States) Defence Science Board, The role of autonomy in DoD systems, Office of the Undersecretary of Defence for Acquisition, Technology and Logistics, Washington, D.C., July 2012, p. 23, available at: https://fas.org/irp/ agency/dod/dsb/autonomy.pdf. 
alternatives, without depending on human oversight and control."11

The line between the systems that help the pilot and an "autonomous" device is surprisingly hard to identify. Human control may still be significant in an aircraft with autonomous functionality. For example, in an aircraft with the pilot on board, or a remotely piloted aircraft, even when some functions are autonomous, the element of human control and ability to communicate means that there is a clear understanding of how the aircraft will respond to the environment. Initially, aerial navigation required pilots to use visual references on the ground in order to find the way and to keep clear of clouds, ${ }^{12}$ limiting the conditions under which, and the altitude at which, they could fly. Today, aircraft fly higher, longer and further because they are supported by navigational technologies which rely extensively on a range of automated systems that communicate information using technologies such as the radionavigation system (for example, the global positioning system). This has made flying "faster, safer and more reliable than ever before." 13 The question is how far along the autonomy spectrum those developments can go without changing the fundamentals of being an aircraft and the ability of the craft to comply with international legal requirements, particularly regarding safety and communication.

There has clearly been an increase in the automation of several systems that previously required clear and meaningful communication between on-board pilots and pilots on board other planes, as well as ground crews. These include collision avoidance systems, low-visibility

${ }^{11}$ United Kingdom Ministry of Defence, above note 7, p. 13; see further Ian Henderson and Bryan Cavanagh, "Unmanned Aerial Vehicles: Do They Pose Legal Challenges?", in Hitoshi Nasu and Rob McLaughlin (eds), New Technologies and the Law of Armed Conflict, Asser Press, The Hague, 2013; Scott Maloney, "Legal and Practical Challenges Associated with the use of Unmanned Aerial Vehicles in the Maritime Environment", Soundings, No. 11, May 2016, pp. 5-6.

${ }_{12}$ Australian Civil Aviation Safety Authority, Visual Flight Rules Guide, Version 6, 2018.

${ }^{13}$ Royal Australian Air Force, "Automated Aircraft Systems To Crew or Not To Crew: That is the question", Pathfinder-Air Power Development Centre Bulletin, No. 243, May 2005. See further the discussion of the early attempts at automated aircraft in the late 1980s. 
guidance and satellite communications worldwide. ${ }^{14}$ However, an autonomous military aircraft that is using covert tactics to achieve a military objective may have to balance the military advantage that can be obtained from being able to deactivate many of these automated communication systems, with the legal requirements to ensure the safety of civil aviation through proper communications with safety authorities. It is those aircraft which have their key communication functions operating with autonomy and without a link to human intervention and oversight that are the focus of this piece.

\section{International Legal Frameworks for Military Aircraft with Autonomous Functions}

There is no overarching international law defining and regulating military aircraft. As Milde observes, "the issue is not addressed in international law with any specificity... The practice of States that could form a basis for the development of customary law is... often shrouded in secrecy. The problem has been also mostly ignored in the legal research and literature." 15 The laws pertaining to military aircraft therefore require a consideration of the legal frameworks applicable in armed conflict (often referred to as international humanitarian law) as well as the laws of civil aviation..$^{16}$ In addition to the rules of international humanitarian law, to which this paper will return in Part VI, three instruments are particularly relevant:

- the 1923 Hague Rules of Aerial Warfare (Hague Rules) ${ }^{17}$

14 See further Charles E. Billings, Aviation Automation: The Search for a Human-Centred Approach, Lawrence Erlbaun Associated, New Jersey, 1997, Chapter 6; P. Mendes de Leon, above note 9 , p. 305.

${ }^{15}$ Michael Milde, International Air Law and ICAO, $3^{\text {rd }}$ ed., Eleven International Publishing, The Hague, 2016, p. 65.

16 See further Heinz Hanke, "The 1923 Hague Rules of Air Warfare: A contribution to the development of international law protection civilians from air attack", International Review of the Red Cross, 1991, No. 3, pp. 139-172 (published in German with English translation used from CUP) for a description of the historical reasons why this area is so controversial and has made regulation difficult.

${ }^{17}$ Hague Rules of Aerial Warfare, 1923 (hereinafter "Hague Rules"). 
- the more recent 2013 Program on Humanitarian Policy and Conflict Research Manual on International Law Applicable to Air and Missile Warfare (HPCR Manual) ${ }^{18}$ and

- the principal document of the international civil aviation legal framework, the 1944 Convention on International Civil Aviation (Chicago Convention), ${ }^{19}$ as well as the documentation of the International Civil Aviation Organisation (ICAO). ${ }^{20}$

A collective reading of these three frameworks demonstrate that autonomous aircraft are included in the definition of aircraft and that as such, autonomous military aircraft will have to comply with the international legal rules which refer to State aircraft, military aircraft and the safety of civil aviation.

\section{Hague Rules}

The Hague Rules were inspired by the First World War and drafted in 1923 following a Commission of Jurists. The Hague Rules were never formally incorporated in a treaty by States and are therefore not binding international law in their own right. However, they are acknowledged as being highly persuasive, if not constituting customary international law. ${ }^{21}$ The Hague Rules do not mention autonomous aircraft. This is arguably surprising given that an early version of autonomy in balloons (projectiles automatically deployed from uncrewed balloons) had already led to legal

18 The Program on Humanitarian Policy and Conflict Research, Manual on International Law Applicable to Air and Missile Warfare, Cambridge University Press, Cambridge, 2013 (hereinafter "HPCR Manual").

${ }^{19}$ Convention on International Civil Aviation, 15 UNTS 295, 7 December 1944 (entered into force 4 April 1947) (hereinafter "Chicago Convention").

${ }^{20}$ Paul Stephen Dempsey, Public International Air Law, McGill University, Montreal, 2008, p. 30 .

${ }^{21}$ Ian Henderson and Patrick Keane, "Air and missile warfare", in Rain Liivoja and Tim McCormack (eds), Routledge handbook of the Law of Armed Conflict, Routledge, Abingdon, 2016, p. 282. 
concerns being raised. ${ }^{22}$ Article 1 of the Hague Rules provides that "the rules of aerial warfare apply to all aircraft, whether lighter or heavier than air, irrespective of whether they are, or are not, capable of floating on water." The accompanying commentary to the Hague Rules (published by way of General Report in 1924) notes that:

[n]o attempt has been made to formulate a definition of the term "aircraft", nor to enumerate the various categories of machines which are covered by the term. A statement of the broad principle that the rules adopted apply to all types of aircraft has been thought sufficient, and Article 1 has been framed for this purpose. ${ }^{23}$

As such, although autonomy is not mentioned, there is nothing in the Hague Rules definition of aircraft that would exclude autonomous aircraft.

The Hague Rules do however establish four requirements for "any aircraft operated by the armed forces of a State." 24 The aircraft shall: (i) bear an external mark indicating its nation and military character; ${ }^{25}$ (ii) be under the command of a person duly commissioned or enlisted in the

${ }^{22}$ Declaration (IV,1), to Prohibit, for the Term of Five Years, the Launching of Projectiles and Explosives from Balloons, and Other Methods of Similar Nature, 29 July 1899 (entered into force 4 September 1900), applicable for 5 years and extended by Declaration (XIV) Prohibiting the Discharge of Projectiles and Explosives from Balloons, 18 October 1907 (entered into force 27 November 1909). The 1907 declaration was due to expire at the close of this projected Third Peace Conference. No Third Peace Conference has ever taken place. It is therefore technically still in application. That these projectiles "may just as easily hit inoffensive inhabitants as combatants, or destroy a church as easily as a battery" being the reason for their regulation: Division of the Law of Carnegie Endowment for International Peace, The Proceedings of the Hague Peace Conferences: The Conference of 1899, Oxford University Press, New York, 1920, p. 280 (comments by Captain Crozier, representing the United States in the First Commission, Third Meeting, June 22, 1899).

23 "Commission of Jurists to Consider and Report upon the Revision of the Rules of Warfare", The American Journal of International Law, Vol. 32, No. 1, January 1938, p. 12.

${ }^{24}$ Hague Rules, above note 18; see also Louise Doswald-Beck (ed.), San Remo Manual on international law applicable to armed conflicts at sea, Cambridge University Press, New York, 1995, Art. 13(j).

${ }^{25}$ Hague Rules, above note 18, Art. III. 
military service of the State, ${ }^{26}$ (iii) be exclusively crewed by military ${ }^{27}$; (iv) and have the members of the crew wear a fixed distinctive emblem of such character as to be recognizable at a distance in case they become separated from their aircraft. ${ }^{28}$ This will be discussed further below in Part 3.4.

\section{HPCR Manual}

The HPCR Manual, like the Hague Rules, is not binding on States. Rather, it is the product of a series of expert meetings which took place over a period of six years resulting in a "methodical and comprehensive reflection on international legal rules applicable to air and missile warfare, drawing from various sources of international law." ${ }^{29}$ It is a "highly persuasive, but not authoritative, exposition of the relevant law." 30

The HPCR Manual provides significant guidance around autonomous aircraft, adopting a definition of military aircraft that incorporates autonomous aircraft. Section $\mathrm{A}(1)(\mathrm{x})$ provides that military aircraft means aircraft:

(i) operated by the armed forces of a State;

(ii) bearing the military markings of that State;

(iii) commanded by a member of the armed forces; and

(iv) controlled, [crewed] or preprogrammed by a crew subject to regular armed forces discipline.

The commentary to the Manual demonstrates that the inclusion of remote and autonomous craft was clear in the minds of the drafters:

Today, [uncrewed aerial vehicles] as well as [uncrewed combat aerial vehicles] also qualify as military aircraft, if the persons remotely controlling them are subject to regular armed forces discipline. The same holds true for

\footnotetext{
${ }^{26}$ Hague Rules, above note 18, Art. XIV.

${ }^{27}$ Hague Rules, above note 18, Art. XIV.

${ }^{28}$ Hague Rules, above note 18, Art. XV; see also I. Henderson and B. Cavanagh, above note 12, p. 197.

${ }^{29}$ HPCR Manual, above note 19, p. vii.

${ }^{30}$ I. Henderson and P. Keane, above note 22, p. 283.
} 
autonomously operating [uncrewed aerial vehicles], provided that their programming has been executed by individuals subject to regular armed forces control. ${ }^{31}$

That said, there is no actual discussion in the commentary of what the inclusion of autonomous vehicles means for the exercise of the various rights and obligations of the aircraft. This will be also be discussed further below in Part 3.4.

\section{Chicago Convention}

Civil aviation has a broad definition of an aircraft, which covers "any machine that can derive support in the atmosphere from the reactions of the air other than the reaction of the air against the earth's surface." 32 This includes a range of both lighter and heavier than air devices such as balloons, airships, gliders, gyroplanes, helicopters, ornithopters and rotorcraft. ${ }^{33}$ While there is no mention of autonomy in the Chicago Convention (although Article 8 does mention "aircraft capable of being flown without a pilot"), aircraft with autonomous functions are considered "aircraft" for the purposes of international law. The ICAO has noted that in fact "[e]ach category [e.g., helicopter, ornithopter, rotorcraft] of aircraft will potentially have un[crewed] versions in the future." 34 The ICAO has further clarified that the definition includes uncrewed aircraft that are programmed and autonomous:

An [uncrewed] aerial vehicle is a pilotless aircraft... which is flown without a pilot-in-command on-board and is either remotely and fully controlled from another place

31 "Commentary to the HPCR Manual on International Law Applicable to Air and Missile Warfare", in HPCR Manual, above note 19, p. 38-39 (hereinafter "HPCR Manual Commentary").

${ }^{32}$ Chicago Convention, above note 20, Annex 7: Aircraft Nationality and Registration Marks, $5^{\text {th }}$ ed., July 2003, section 1.

${ }^{33}$ Ibid.; see also P. Mendes de Leon, above note 9, p. 13.

${ }^{34}$ International Civil Aviation Organization (ICAO), Unmanned Aircraft Systems, ICAO, Montreal, 2011, para 2.5. 
(ground, another aircraft, space) or programmed and fully autonomous. $^{35}$

The Chicago Convention, which distinguishes between civil and State aircraft, defines State aircraft as "aircraft used in military, customs and police services." ${ }^{36}$ Article 3(a) of the Chicago Convention, like many other instruments of civil aviation law, ${ }^{37}$ specifically provides that it "shall not be applicable to state aircraft." Some States have expressed strong opinions to the effect that the Chicago Convention, and therefore the ICAO, does not have any jurisdiction when it comes to State aircraft. During the drafting of the Chicago Convention, the view that "there was a clear border between civil and military aviation and that there was no need to regulate the latter internationally" was held. ${ }^{38}$ However, the drafting also recognized the fact that all aircraft could potentially be navigating the same airspace and that consequences would flow from this. ${ }^{39}$ As such, some rules of civil aviation are in fact applicable to State aircraft (see also below at Parts IV and V) and the aircraft definition in the civil aviation context is informative.

\section{Military Aircraft with Autonomous Functions}

The collective reading therefore of the Hague Rules, HPCR Manual, Chicago Convention and ICAO document on Unmanned Aircraft Systems demonstrates that autonomous aircraft are either included in, anticipated by or not excluded from the definitions of aircraft-whether civil or military. ${ }^{40}$ In Parts IV-VI of the paper, the resulting obligations of

${ }^{35}$ ICAO, above note 35, para. 2.1: referencing both the Global Air Traffic Management Operational Concept (Doc 9854) and the $35^{\text {th }}$ Session of the ICAO.

${ }^{36}$ Chicago Convention, above note 20, Art. 3(b).

37 See for example Convention for the Suppression of Unlawful Acts Against the Safety of Civil Aviation, 974 UNTS 177, 23 September 1971 (entered into force 26 January 1973), Art. 4.

38 Jiri Hornik, "Article 3 of the Chicago Convention", Annals of Air \& Space Law, Vol.26, June 2001, pp. 114-115.

39 J. Hornik, above note 39, p. 115. Hornik's proposal is in fact for a new all-encompassing Convention "which would deal with navigation in airspace and its basic principles as a whole, in particular with those related to safety" (at p. 142).

${ }^{40}$ Chicago Convention, above note 20, section 1; ICAO, above note 35, para. 2.1; HPCR Manual, above note 19, Section A(1)(x). 
these autonomous military aircraft are discussed. Two points, however, must be recalled when considering autonomous military aircraft and their legal obligations.

Firstly, the ICAO, despite grouping all potential levels of autonomous functionality together, has taken the view that autonomous aircraft will have some unique characteristics that may be problematic. This is evident from the observations that, although remotely piloted aircraft "will be able to integrate into the international civil aviation system in the foreseeable future" because the remote pilot can ensure "safe and predictable operation of the aircraft", "fully autonomous aircraft" may not be able to. ${ }^{41}$ This is an acknowledgment that the level of autonomy may alter the fundamentals of the aircraft. In doing so, autonomy may challenge the ability of the aircraft to give effect to some of the legal obligations of an aircraft, such as those pertaining to communication, which arise by virtue of the legal frameworks for both civil and State aircraft discussed below.

Second, the criteria of military aircraft enshrined in the Hague Rules, HPCR Manual and customary law require that military aircraft: (i) bear an external mark indicating its nation and military character, ${ }^{42}$ (ii) be under the command of a person duly commissioned or enlisted in the military service of the State ${ }^{43}$ (iii) be exclusively crewed by military ${ }^{44}$; and (iv) have the members of the crew wear a fixed distinctive emblem of such character as to be recognizable at a distance in case they become separated from their aircraft. ${ }^{45}$ That is, the definition of a military aircraft is not concerned with technical aspects of aircraft. Indeed, an early attempt at a technical approach to a definition of military aircraft - as part of the postVersailles Peace Treaty negotiations in 1922-was described as "ludicrous". ${ }^{46}$ Rather, the definition is concerned with the aircraft's military nature - that it is being commanded and crewed (on-board or remotely) by military personnel. It is arguable that some of the criteria

${ }^{41}$ ICAO, above note 35 , para. 2.2 .

${ }^{42}$ Hague Rules, above note 18, Art. III.

${ }^{43}$ Hague Rules, above note 18, Art. XIV.

${ }^{44}$ Hague Rules, above note 18, Art. XIV.

${ }^{45}$ Hague Rules, above note 18, Art. XV; see also I. Henderson and B. Cavanagh, above note 12, p. 197.

${ }^{46}$ See further M. Milde, above note 16, pp. 66-67. 
used in the Hague Rules are, today, no longer strictly necessary and/or at least less important than they were. For example, Henderson has argued that the issue of aircraft markings "may" be "losing its legal significance" 47 given that the small size of some craft is rendering these markings not possible to identify ${ }^{48}$ Further, State practice does not demand that there be a crew on board the aircraft. ${ }^{49}$ However, the inclusion of the requirement of command, by a person duly commissioned or enlisted in the military service of the State ${ }^{50}$ is less easy to dismiss, with command being such a central concept to military operations.

An open question remains as to the practical implications of the inclusion of autonomous aircraft as military aircraft for the exercise of the accompanying rights and obligations of military aircraft. ${ }^{51}$ As was pointed out in discussing the HPCR Manual commentary above, there is a general lack of discussion about what the inclusion of autonomous vehicles means for the exercise of the various rights and obligations of an aircraft. The United Kingdom Joint Doctrine notes that the United Kingdom "does not possess armed autonomous aircraft systems and it has no intention to develop them" (emphasis added). ${ }^{52}$ But what about non-weaponized military aircraft? For the Australian Defence Force "command is a fundamentally human function that cannot be conducted by machines" (emphasis added).$^{53}$ How does this sit with autonomy and the Australian

${ }^{47}$ I. Henderson and B. Cavanagh, above note 12, p. 198.

${ }^{48}$ For a more detailed discussion of military aircraft markings see Ian Henderson, "International law concerning the status and marketing of remotely piloted aircraft", Denver Journal of International Law and Policy, Vol. 39, No. 4, 2011, pp. 615-628.

${ }^{49}$ I. Henderson and B. Cavanagh, above note 12, pp. 198-9; HPCR Manual Commentary, above note 32 , p. 38.

${ }^{50}$ Hague Rules, above note 18, Art. XIV.

51 See further Eve Massingham, Simon McKenzie and Rain Liivoja, "Command in the Age of Autonomy-Unanswered Questions for Military Operations", Opinio Juris - AI and Machine Learning Symposium, 1 May 2020, available at: https://opiniojuris.org/ 2020/05/01/ai-and-machine-learning-symposium-command-in-the-age-of-autonomyunanswered-questions-for-military-operations/.

${ }^{52}$ United Kingdom Ministry of Defence, above note 7, p. 43.

${ }^{53}$ Australian Defence Force, ADF Concept for Command and Control of the Future Force, Commonwealth of Australia, 2018, p. 18, available at: https://theforge.defence.gov.au/ sites/default/files/adf_concept_for_command_and_control_of_the_future_force_v.1_si gned.pdf. 
government plans for the development of "trusted autonomous systems"? 54 States need to turn some attention to this. If they do not, the practice of those States who are already deploying increasingly autonomous craft and who are including them in their doctrine will emerge as the default framework without due consideration by the broader international community as to whether the traditional criteria in the Hague Rules should be maintained or modified.

For completeness, it should be noted that airborne munitionsand in particular loitering munitions $s^{55}$-are not military aircraft. While many missiles and rockets would not meet the definition of an aircraft, ${ }^{56}$ technology is increasingly allowing munitions to behave in ways more traditional to aircraft. Often, the design of an autonomous aircraft will mean it is expendable if necessary, but they are not designed to be destroyed. The intention is that they will return to base. ${ }^{57}$ This is fundamentally different from a munition. As such, airborne munitions are excluded from the discussion of aircraft even if they would otherwise meet the definition of aircraft. Further, armament is not itself a factor that makes something a military aircraft. ${ }^{58}$

\section{Autonomous State Aircraft and the Safety of Civil Aviation}

The Chicago Convention provisions require that States ensure civil aircraft are safe. For example, Article 3 bis of the Chicago Convention provides that "every State must refrain from resorting to the use of weapons against civil aircraft in flight and that, in case of interception, the lives of persons on board and the safety of aircraft must not be endangered." Further, while the Chicago Convention does not purport to

${ }^{54}$ Australian Government Department of Defence, Defence Industry Policy Statement, 2016, pp. 31-32, available at: https://www.defence.gov.au/WhitePaper/Docs/2016-DefenceIndustry-Policy-Statement.pdf.

${ }^{55}$ See further Charlie Gao, "Why Loitering Munitions Are the Newest and Deadliest Threat", The National Interest, 17 September 2019, available at: https://nationalinterest. $\mathrm{org} / \mathrm{blog} / \mathrm{buzz} /$ why-loitering-munitions-are-newest-and-deadliest-threat-81241.

${ }^{56}$ See further P. Mendes de Leon, above note 9, p. 13.

57 See also discussion regarding weapons at sea not meeting the definition of a vessel in Craig Allen, "Determining the Legal Status of Unmanned Maritime Vehicles: Formalism vs Functionalism", Journal of Maritime Law and Commerce, Vol. 49, No. 4, 2018, p. 495.

${ }^{58}$ HPCR Manual Commentary, above note 32, p. 38 (see for example $\mathrm{ftn} 63$ ); see also C. Allen, above note 58 , p. 495. 
regulate State aircraft directly, it specifically requires that States ensure that State aircraft have "due regard" for the safety of civilian aircraft. Article 3(d) provides that "when issuing regulations for their state aircraft ... [States] will have due regard for the safety of navigation of civil aircraft." The Chicago Convention codified the due regard principle as it relates to State aircraft. ${ }^{59}$ Bourbonniere and Haeck describe this provision in the following way. Due regard "creates an obligation on States to regulate State aircraft in order to ensure that State aircraft exercise appropriate attention, as well as, heed and care for the safety of the course and position of civil aircraft avoiding obstruction to the course of and collisions with civil aircraft." ${ }^{160}$ Ells is even more specific in noting that "[a]t the risk of vast oversimplification, having or exercising due regard means assuming responsibility for the safety of other aircraft in the immediate vicinity without reliance on an air traffic control system." 61 The question therefore is: whether in automating some of the functions of aircraft, State aircraft systems can still have "due regard for the safety of navigation of civil aircraft" and thus meet the legal requirements?

Autonomy can clearly enhance safety. ${ }^{62}$ However, that autonomous aircraft have potential to cause significant safety concerns is acknowledged by the ICAO. To date the issue has been left as one for States to deal with. Milde cites the ICAO observation that "there is no apparent need to amend... the Convention" noting that "[n]ational legislations gradually" are addressing this. ${ }^{63}$ That said, the understanding of potential challenges in the legal framework is acknowledged. A working paper of the ICAO in 2015 noted that given the:

efforts of the international aviation community to address the myriad technical and operational issues arising from

${ }^{59}$ M. Bourbonniere and L. Haeck, above note 6, p. 912.

${ }^{60} \mathrm{M}$. Bourbonniere and L. Haeck, above note 6, p. 916.

${ }^{61}$ Mark Ells, "Unmanned state aircraft and the exercise of due regard", Issues in Aviation Law and Policy, Vol. 13, No. 2, 2014, p. 323.

${ }^{62}$ Christoph Torens, Johann Dauer, Florian Adolf, "Towards Autonomy and Safety for Unmanned Aircraft Systems" in Umut Durak et al. (eds), Advances in Aeronautical Informatics, Springer, Cham, 2018, p. 105.

${ }^{63}$ M. Milde, above note 16 , p. 46. As Dempsey points out, domestic laws predated international laws. For example, in 1784, for example, a directive was issued by the Paris police prohibiting unauthorised balloon flights: P. Dempsey, above note 21, p. 11. 
the removal of the pilot from the aircraft, a reexamination of specific aspects of international air law is warranted to ascertain the adequacy and efficacy of the existing legal framework. ${ }^{64}$

There are therefore questions across the civil aviation space about the need for further regulation and for understanding the distinctions between aircraft employing these new technologies and more traditional aircraft. ${ }^{65}$ These are not settled questions, and as more and more State aircraft employ greater levels of autonomy, States need to consider, in relation to different levels of autonomy, whether the technology does in fact allow for "due regard" of the safety of civil aviation. The acceptable standard will also need to be considered. Is this to be the standard of crewed aircraft? That is, should autonomous aircraft be required to pose no greater risk than that which would be posed by a crewed aircraft? ${ }^{66}$ Or should the autonomous technology be held to a higher standard?

A costly example of the importance of the military balancing military capability demands with the ability to comply with civil aviation safety regulations is the German Euro Hawk project. This project was cancelled, after more than USD790 million had been spent, because it would not be cleared to fly by European civil aviation. ${ }^{67}$ "The Euro Hawk lacked an on board 'sense and avoid system' to avoid collisions, a prerequisite to obtain flight permission in the [European Union]." "sense" component on the "sense and avoid system" requires the aircraft to use a range of communication methods to both broadcast and receive

${ }^{64}$ Study of Legal Issues Relating to Remotely Piloted Aircraft, ICAO Doc. LC/36-WP/24, 30 November - 3 December 2105, Appendix A-1, available at: https://www.icao. int/Meetings/LC36/Working\%20Papers/LC\%2036\%20-\%20WP\%202-4.en.pdf.

${ }^{65}$ See further Ridha Aditya Nugraha, Deepika Jeyakodi and Thitipon Mahem, "Urgency for legal framework on drones: Lessons for Indonesia, India, and Thailand", Indonesia Law Review, Vol. 6, No. 2, 2016, p. 153.

66 See further M. Ells, above note 62, p. 343.

${ }^{67}$ Stephen Ceccoli and Matthew Crosston, "Diffusion and policy transfer in armed UAV proliferation: the cases of Italy and Germany", Policy Studies, Vol. 40, No. 2, 2019, p. 122.

${ }^{68}$ Deanne Corbett, "Germany Seeks to Revive Euro Hawk Program", Defence News, 16 January 2015, available at: https://www.defensenews.com/air/2015/01/16/germanyseeks-to-revive-euro-hawk-program/. 
information. ${ }^{69}$ This inability of the craft to meet the basic communication requirements to allow safe interactions with civilian aircraft ultimately contributed to it being unable to serve its military purpose.

Having due regard for the safety of navigation of civil aircraft necessarily requires an aircraft to be able to signal and communicate in a manner consistent with international protocols in order to avoid hazards and to avoid being a hazard. As has been earlier flagged, the value of an autonomous military aircraft may well be linked to its ability to operate in a communications-denied environment. Legal exemptions for military devices might mean that a device deliberately designed with a limited capacity for communication may not have any difficulties operating in some domestic contexts. For example, in Australia, where the radio spectrum is regulated by the Radiocommunications Act 1992 (Cth), Article 24 provides that the Act does not apply to acts or omissions by Defence members "the purpose of which relates to... research for purposes connected with defence" or "intelligence". However, where these criteria are not met, the Act imposes penalties on persons using radiocommunications which defence personnel may have to comply with. Further, Hornik observes that in fact many States' "national air laws contain a provision that to various extents subjects State aircraft to the same regulations applicable to civil aircraft" and that this is "undeniably an important aspect of promoting the safety of navigation." "If the result is that the aircraft cannot comply with the communication requirements of domestic legal frameworks this will be a breach of the domestic law, but may also mean that the craft cannot have due regard for the safety of civil aviation and is therefore also violating international civil aviation law. Depending on the nature of the mission, States may need to ensure that autonomous military aircraft are able to comply with civilian communication protocols designed for the safety of civil aviation while completing their flight.

${ }^{69}$ See for example Giancarmine Fasano et al., "Sense and Avoid for Unmanned Aircraft Systems", IEEE Aerospace and Electronic Systems Magazine. Vol. 31, No. 11, 2016, p. 82.

${ }^{70}$ J Hornik, above note 39, p. 109. 


\section{Autonomous State Aircraft and Navigation Rights}

State aircraft have to comply with restrictions on their navigational rights. These rules are significantly more stringent than the requirements for any civil flight that enters the sovereign territory of another State (as detailed in the Chicago Convention ${ }^{71}$ ), and being able to communicate with other aircraft and with air traffic control is key.

According to treaties and customary international law, State aircraft are able to fly over the:

1. land areas and territorial waters adjacent thereto under their State's sovereignty, ${ }^{72}$

2. land areas and territorial waters adjacent thereto of any State that has given express prior permission; ${ }^{73}$

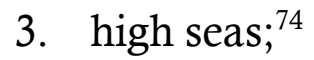

4. straits which are used for international navigation between one part of the high seas or an exclusive economic zone; ${ }^{75}$

5. archipelagic sea lanes, ${ }^{76}$

6. "other parts of the earth's surface not subject to any State's jurisdiction, [which] is free to the aircraft of all States"; $; 7$ and

7. areas of "undetermined sovereignty". ${ }^{78}$

The freedom of overflight of aircraft applies the same principles of the freedom of the high seas-namely, that there is a right of "unimpeded

${ }^{71}$ See for example Chicago Convention, above note 20, Arts. 5 and 6.

${ }^{72}$ Chicago Convention, above note 20, Art. 2.

${ }^{73}$ Chicago Convention, above note 20, Art. 3(c).

${ }^{74}$ United Nations Convention on the Law of the Sea, 1833 UNTS 3, 10 December 1982 (entered into force 16 November 1994), Art. 87(1)(b) (hereinafter "UNCLOS").

${ }^{75}$ UNCLOS, above note 75, Arts. 37 and 38.

${ }^{76}$ UNCLOS, above note 75, Art. 54. Archipelagic waters are determined by drawing straight baselines connecting the outer edges of qualifying islands in an archipelago. Archipelagic sea lanes passage allows an archipelagic State to set aside sea lanes and air routes through its archipelagic waters.

77 P. Dempsey, above note 21, p. 13; see also Hague Rules, above note 18, Art. XII.

${ }^{78}$ M. Bourbonniere and L. Haeck, above note 6, p. 895. Note particularly, footnote 38 regarding Antarctica. 
passage" but that this passage is subject to limitations including the duties to protect life and the environment and to prevent illicit activities such as piracy, slavery, trafficking and unauthorized broadcasting. ${ }^{79}$

While the paper's focus is on military air assets there is clearly an overlap between naval warfare and land warfare rules. ${ }^{80}$ Further, the United Nations Convention on the Law of the Sea (UNCLOS), which governs the use of the seas and oceans, provides for the regulation of overflight in the different zones recognized by the law of sea. There are communications requirements for aircraft as part of UNCLOS as well. For example, it is a requirement on aircraft exercising overflight rights to "at all times monitor the radio frequency assigned by the competent internationally designated air traffic control authority." ${ }^{81}$ States must be sure that the technology of the autonomous State aircraft does not interfere with this communication obligation.

A State aircraft that enters prohibited airspace without permission risks being shot down. "The trespassing aircraft could be intercepted and identified, directed to leave, forced to land at a designated airfield, or ultimately have a warning shot fired, and, if necessary, have its flight terminated." 82 While the "disposable" nature of autonomous aircraft means that the implications of downing the craft is much less serious than the downing of crewed craft, in many cases, there will not necessarily be any significant consequence from a short duration of an autonomous aircraft entering the airspace of another State.

That said, the consequences of any State aircraft, crewed or otherwise, straying into foreign territory could also be more far-reaching in terms of starting a military engagement. State aircraft straying into the airspace of another State without permission could be seen as contravening Article 2(4) of the UN Charter which prohibits the "threat or use of force against the territorial integrity or political independence of any state." Given that there may be non-hostile reasons for State aircraft to fly into foreign airspace-for example, bad weather, accident or other

\footnotetext{
${ }^{79}$ Douglas Guilfoyle, "Article 87" in Proelss (ed.), United Nations Convention on the Law of the Sea: A Commentary, Beck, Hart and Nomos, Germany, 2017, pp. 681-2.

${ }^{80}$ See further Franciso Javier Guisández Gómez, "The Law of Air Warfare", IRRC, Vol. 323, 1998; see also, I. Henderson and B. Cavanagh, above note 12, p. 198.

${ }^{81}$ UNCLOS, above note 75, Art. 39 (3)(b).

${ }^{82}$ M. Bourbonniere and L. Haeck, above note 6, p. 946.
} 
force majeure ${ }^{83}$-during peacetime, State practice has seen alignment with the customary law principles for civil aircraft that prohibit their downing in these cases ${ }^{84}$ However, there is always the possibility of the aircraft being attacked in circumstances where there was no hostile intent. It is also perhaps increasingly likely that these aircraft will be used to push the boundaries of sovereignty for military (in particular surveillance) purposes which may result in States being less inclined to treat State aircraft in the way civil aircraft have been treated in the past.

There are measures in place in order to protect sovereignty which may require aircraft to communicate. For example, some States have implemented a "reporting and identifying regime for aircraft bound for coastal and island states" which seeks communication from the aircraft while still in international airspace as to its future intention to enter that airspace.$^{85}$ Although aircraft not entering the relevant States' airspace do not have to identify themselves, this is an example of a recognized custom of States where communication plays a significant role.

It is therefore important that the autonomous functionality on any autonomous aircraft allows for compliance with these navigational principles in order to prevent international incidents-including the possible downing of aircraft when no hostile intent was present. Again, as it is with the safety of civil aviation, communication is vital here. Autonomous aircraft must be programmed in such a way as to ensure that they can comply with the relevant communications protocols. In the case of a communications-denied environment or other communications challenge, the aircraft must be appropriately programmed to ensure that it does not fly into foreign airspace unintentionally. In the event that this does occur, "actions on" making this transgression must also include an ability to comply with civil aviation communications protocols to alert the relevant authorities to the situation.

${ }^{83}$ M. Bourbonniere and L. Haeck, above note 6, pp. 946-8.

${ }^{84}$ Ibid.

${ }^{85}$ Lt Col Andrew S. Williams, "Aerial Reconnaissance by Military Aircraft in the Exclusive Economic Zone", in Peter Dutton (ed.), Military Activities in the Exclusive Economic Zone, Naval War College China Maritime Studies Institute, Unites States of America, December 2010, p. 51. 


\section{Military Aircraft Rights and Obligations under International Humanitarian Law and Communication in Aid of Civilian Safety}

The final point addressed in this paper are the communications functions that allow an autonomous aircraft to exercise the rights and obligations of a military aircraft without the safety of civilians and civilian aircraft being compromised. In Parts IV and V, the discussion has looked at the obligations of State aircraft. Military aircraft are a particular subset of State aircraft. ${ }^{86}$ However, there is necessarily a difference between State aircraft - which have certain navigational and other rights - and military aircraft, which not only have these same navigational rights (and limitations), but also have belligerent rights. Belligerent rights are those rights that attach to belligerency, or "the condition of being in fact engaged in war." 87 They allow "actions in wartime that would not be permitted under the law of peace." ${ }^{88}$ Belligerent military aircraft have the right to engage in hostilities (including specific communication rights such as the "transmission during flight of military intelligence" ${ }^{89}$ ) in compliance with international law and, more specifically, international humanitarian law. In order to exercise belligerent rights and obligations, an autonomous aircraft must not only have the status of a "State aircraft" but specifically be a "military aircraft".

If an autonomous aircraft is a military aircraft, then it will have belligerent rights. It should be noted that because belligerent rights are just that - rights - not obligations, not all military aircraft need to be able to exercise them, and so being able to do so is not a requirement of being a military aircraft. However, having these rights can be hugely significant. Military aircraft have potential impacts on civilians and civilian aircraft in the exercise of their rights and obligations. In times of war, States may regulate aircraft movement within their jurisdiction. ${ }^{90}$ This allows States to require aircraft (including belligerent non-military aircraft and neutral

${ }^{86}$ Chicago Convention, above note 20, Art. 3(b).

${ }^{87}$ Encyclopedia Britannica, "Belligerency", available at: https://www.britannica.com/ topic/belligerency.

${ }^{88}$ Lawrence Hill-Cawthorne, "Rights under International Humanitarian Law", European Journal of International Law, Vol. 28, No. 4, 2017, pp. 1188.

${ }^{89}$ Hague Rules, above note 18, Art. XVI.

${ }^{90}$ Hague Rules, above note 18, Art. XII. 
aircraft) to "make the nearest available landing."91 Belligerent commanders can also "prohibit the passing of neutral aircraft in the immediate vicinity of the force or may oblige them to follow a particular route." ${ }^{92}$ Non-compliant aircraft "may be fired upon." ${ }^{93}$ Further, pursuant to the authorization of a no-fly zone, ${ }^{94}$ a "delinquent aircraft-which has been subject to the full range of non-lethal warning and escalation of force measures", there may be some situations when the use of force may be allowed. ${ }^{95}$

As such, should an autonomous military aircraft seek to exercise these rights, it would need to ensure the legal requirements were appropriately complied with. Communicating warnings appropriately is therefore absolutely essential to a military aircraft's activities. This raises a number of questions. Can an autonomous military aircraft effectively give warnings, effectively receive warnings, and effectively receive and act on communications in response to warnings issued? These are legal questions the developers of these aircraft must consider. Autonomous military aircraft communications have to be able to be executed in accordance with global protocols such that miscommunication is not the source of civilian aircraft being destroyed.

In addition, autonomous military aircraft must be able to comply with the obligations of military aircraft. A key obligation of military medical aircraft is that they shall also "obey every summons to land." 96 This is articulated in Article 36 of the First Geneva Convention and Article 30 of the Second Geneva Convention. The Updated Commentary to the Geneva Conventions acknowledges the broad nature of the term "aircraft" and that indeed, in the future, military medical aircraft that are

${ }^{91}$ Hague Rules, above note 18, Arts. XXXIII, XXXV.

92 Hague Rules, above note 18, Art. XXX.

${ }^{93}$ Hague Rules, above note 18, Arts. XXX, XXXIII, XXXIV, XXXV.

${ }^{94}$ See further Rob McLaughlin, "United Nations Security Council Practice in Relation to Use of Force in No- Fly Zones and Maritime Exclusion Zones" in Mark Weller (ed.), The Oxford Handbook of the Use of Force in International Law, Oxford University Press, Oxford, p. 205.

${ }^{95}$ R. McLaughlin, above note 95, p. 6.

${ }^{96}$ Geneva Convention for the Amelioration of the Condition of the Wounded and Sick in Armed Forces in the Field of 12 August 1949, 75 UNTS 31 (entered into force 21 October 1950), Art. 36; Geneva Convention for the Amelioration of the Condition of Wounded, Sick and Shipwrecked Members of Armed Forces at Sea, 12 August 1949, 75 UNTS 85 (entered into force 21 October 1950), Art. 30. 
uncrewed may be a reality and may fall within the scope of Article $36 .{ }^{97}$ The Commentary specifically notes:

[I]t is increasingly likely that States will develop and employ [uncrewed] ground and/or air medical evacuation vehicles that are either remotely controlled or autonomous to collect and transport wounded and sick personnel. As long as they meet the requirement for protection set forth in Article 35 (i.e. being assigned exclusively to medical transportation), there is no reason to exclude such transports from the scope of Article 35. Their protection can only contribute to the humanitarian objectives of the Convention. ${ }^{98}$

There is no set way in which the summons to land must be communicated ${ }^{99}$ Ideally, the parties will have a predetermined method for this-for example, "broadcasting the summons on a pre-approved frequency." 100 However, "the Party issuing the summons to land must take all reasonable measures to ensure that the summons actually reaches the persons in control of the aircraft." 101 Article 14 of the Regulations concerning identification annexed to Additional Protocol I notes that the "standard visual and radio interception procedures prescribed by Annex 2 to the Chicago Convention on International Civil Aviation of 7 December 1944 , as amended from time to time, should be used by the intercepting and the medical aircraft." 102 Autonomous aircraft developers will therefore have to ensure that their aircraft are capable of responding to directions given in accordance with these methods. If they cannot be programmed to respond appropriately, then while they may (arguably)

${ }^{97}$ ICRC, Commentary on the First Geneva Convention: Convention (I) for the Amelioration of the Condition of the Wounded and Sick in Armed Forces in the Field, 2nd ed., ICRC, Geneva, 2016, para. 2440 (hereinafter "Commentary to GCI").

${ }_{98}$ Commentary to GCI, above note 98, para. 2373.

${ }^{99}$ Commentary to GCI, above note 98, para. 2473.

${ }^{100}$ Commentary to GCI, above note 98 , para. 2474.

${ }^{101}$ Ibid.

${ }^{102}$ Protocol Additional (I) to the Geneva Conventions of 12 August 1949, and Relating to the Protection of Victims of International Armed Conflicts, 1125 UNTS 3, 8 June 1977 (entered into force 7 December 1978), Annex I, Art. 13. 
meet the technical definition of a military aircraft or at least of a State aircraft, they will not be able to comply with the legal requirements of being a military medical aircraft and thus lose the protections afforded by international humanitarian law, putting the sick and wounded at risk.

\section{Conclusion}

There is still a lack of clarity about what is going to be feasible in terms of autonomy from a technological perspective. There is also a lack of understanding about what States are willing to pursue in terms of autonomy. An increasing number of armed actors are deploying uncrewed technologies, particularly for tasks such as surveillance and reconnaissance. Many of those developing these technologies have been cautious. Some believe there is some underlying agreement that "until the machine processors equal or surpass humans at making abstract decisions, there's always going to be mission command." 103 That said, many States (and some non-State actors) are developing their capabilities using autonomous technologies, and there is an increasingly vast range of military aircraft with different degrees of autonomous functions currently in the skies, and in civilian airspace, challenging the legal frameworks.

Aircraft with autonomous functions that are employed by the military are already automatically considered military aircraft by many States. Further, in the civilian landscape of the ICAO, aircraft include autonomous aerial vehicles. As aircraft have existed since the beginning of air travel (e.g., balloons), definitions of "aircraft" in the regulatory frameworks were designed to address craft both with pilots on-board and remote to the craft. Although autonomous systems are recognized as having features different to remotely piloted ones, and their full integration into aviation is still developing, the determination of their status as aircraft seems settled.

But regardless of status, exercising both the rights and obligations of State and military aircraft will require autonomous military aircraft to have certain abilities and, importantly, the communication functions to give effect to these rights and obligations. While the very point of

\footnotetext{
${ }^{103}$ Paul Scharre, Army of None, WW Norton and Company, New York, 2018, p. 81, quoting Bradford Tousley of the United States Defence Advanced Research Projects Agency.
} 
autonomous military aircraft in some cases will be to allow for operations in communications-denied environments, their functionalities (and therefore their tasks) must not prevent them from complying with legal frameworks pertaining to the safety of civil aviation and civilians.

Compliance with the civilian aviation regulations requires not only the capacity to communicate consistently with international protocols where necessary, but also having a system to deal with the situation when communications systems fail. Communication challenges of course can also apply to crewed and remotely piloted aircraft without autonomous functionality where problems result in pilots being unable to reach either military or civilian air-traffic control. The communications channels between the operator and the device may be accidentally lost or may be deliberately jammed or hacked. As such, some of these challenges may not be unique to autonomous aircraft. However, given that autonomous military aircraft are often specifically designed with the objective of operating in communications-denied environments, States need to give consideration to ensuring that autonomous military aircraft are able to comply with civilian communication protocols designed for the safety of civil aviation while completing their military missions.

There is a very real question about whether some autonomous military aircraft can appropriately communicate in order to exercise the relevant rights and obligations. Autonomous military aircraft have many possible positive uses, but some certainty is required in the legal sphere. States need to consider whether the autonomous military aircraft they operate obviate danger to civil aircraft, comply with the sovereign rights of aircraft and can give effect to belligerent obligations (as well as exercise belligerent rights where necessary). To not do so would mean further costly undertakings which result in a failure to deliver, but also would put at risk civil aviation and civilians in both peace time and in times of armed conflict. 